Investigaciones Fenomenológicas, n. 9, 2012, 39-68.

e-ISSN: $1885-1088$

\title{
DELIMITACIÓn DE LA EMOCIÓN. ACERCAMIENTO A UNA FENOMENOLOGÍA DEL CORAZÓN*
}

\author{
Natalie Depraz \\ Université de Rouen, Francia \\ natalie.depraz@univ-rouen.fr
}

\begin{abstract}
Resumen: Las emociones hacen referencia, tanto en el lenguaje común como en el filosófico y científico, a una dimensión de la vida subjetiva que no está suficientemente delimitada. El objetivo de este trabajo es el de aproximarnos al fenómeno emocional a través del estudio de varias problemáticas asociadas al mismo. Por un lado, se realiza un análisis etimológico y conceptual de algunas nociones habitualmente relacionadas con las emociones, como es el caso de los términos "afección", "sentimiento", "feeling" o "Stimmung". Por otro lado, se realiza un recorrido por aquellas disciplinas teóricas que implícita o explícitamente contienen una teoría de la emoción, desde la filosofía de Descartes hasta las ciencias cognitivas, pasando por la ética, la estética y la fenomenología. Por último se propone una fenomenología del corazón que permita dar cuenta del tipo de movilidad y de temporalidad propio del régimen emocional, permitiéndonos así tener acceso a un núcleo experiencial.
\end{abstract}

Palabras clave: Emoción, Stimmung, Gemüt, fenomenología, corazón.

\begin{abstract}
Emotions refer, both in common language as well as in philosophical and scientific one, to a dimension of subjective life that is not well enough defined. The aim of this essay is to approach the emotional phenomenon by dealing with several related issues. On the one hand, some notions usually related to emotions, such as affection, feeling or Stimmung, are etymologically and conceptually analysed. On the other hand, a survey is made of the various theoretical disciplines which implicitly or explicitly contain a theory of emotion, from Descartes' philosophy to cognitive sciences, including ethics, phenomenology and aesthetics. Finally, a heart phenomenology is proposed to give account of the kind of mobility and temporality belonging to the emotional regime, enabling us to access an experiential nucleus.
\end{abstract}

Keywords: Emotion, Stimmung, Gemüt, phenomenology, heart.

I. INTRODUCCIÓN: EL RIESGO Y LA APUESTA DE UNA DEFINICIÓN

En la lectura de numerosos artículos y libros, bien se trate de entradas del diccionario o de textos filosóficos -incluso fenomenológicos-, descubrimos que la emoción se encuentra confundida con toda suerte de nociones que dan la impresión de estar en una íntima relación con ella. Sin embargo, esta intuición pide ser precisada: todas estas nociones nublan la aprehensión propiamente

\footnotetext{
* Versión original de este ensayo: Natalie Depraz, "Delimitation de l'émotion. Approche d'une phénoménologie du coeur", Alter. Revue de Phénomenologie 7 (1999) 121-148.
} 
dicha del fenómeno de la emoción. No permiten delimitar su sentido específico, ni tampoco, de otro modo, definir su estatuto preciso.

\section{A. Multiplicidad de nociones conectadas}

¿Cuáles son estas nociones de las que hablamos? Podemos distinguir fácilmente tres series en función de su raíz etimológica:

1) affectio: que ha dado los términos de "afecto", "afección", "afectividad", y que se refiere de modo general al plano de la "facticidad", entendida como aquello que se me impone, que me es dado o que, literalmente, me "hace".

2) sentire, sensus: que nos remite a la esfera del "sentimiento", de la "sensación", y en un sentido más amplio, al plano del "sentir", donde, como veremos, el sentido paradigmático es el del tacto.

3) pathein, pathos: que da lugar al dominio de la "pasión", de lo "patético" y del "padecer", pero que también reclama el ámbito de la "simpatía", la "empatía" y la "compasión", dando lugar a la problemática de la "pasividad".

Con todo, ninguna de estas series - que toman partido bien por 1) la facticidad, bien por 2) el sentir o bien por 3) la pasividad-corresponden a la singularidad de la emoción, al menos en un sentido etimológico, ya que ésta contiene una estrecha relación con otro grupo, que es el del "movimiento" (motus) como moción o incluso como movilidad. En efecto, e-mover [e-mouvoir] significa, literalmente, "poner en movimiento", y viene directamente del latín "exmovere": mover, propulsar, poner o llevar fuera de sí. Si "é-motionner" -y su adjetivo correspondiente "émotionnel" (al que corresponde el "estar emocionado") - es un verbo que no está reconocido por la Academia ${ }^{1}$, traduce sin embargo con gran precisión ese carácter de la e-moción, como movimiento impulsado por otra cosa que yo mismo, que me conduce fuera de mí, sin que tal movimiento contenga implicaciones de dirección o de finalidad: ello explica, sin duda, la utilización del participio "re-movido" ["re-mué"], como sinónimo de "estar emocionado". Estar "re-movido" o, también, estar "re-vuelto", estar "estre-mecido", traducen esta movilidad difusa y efervescente, de la cual no siem-

\footnotetext{
${ }^{1}$ No es posible traducir aquí los conceptos que emplea la autora conservando su sentido en el texto, pues el verbo "é-motionner" (que traduciríamos por "e-mocionar"), en francés, tiene un uso solamente informal, estando en cambio reconocido en el español. Para darnos una idea de lo que Natalie Depraz quiere expresar, tenemos que aludir a un verbo que no existe en español, como sería, por ejemplo, el verbo "e-mover", cuya adaptación francesa sí está reconocida. En efecto, en francés el verbo correcto es "emouvoir" (literalmente "emover"), mientras que "emotionner" ("emocionar") es un verbo coloquial $[\mathrm{N}$. del T.]
} 
pre sabemos determinar su objeto preciso (a saber, la razón o la causa, por un lado, el objetivo o la consecuencia, por otro), y que implica numerosos movimientos (múltiples, dispersos y coexistentes) en una suerte de remolino. La imagen que viene al espíritu, desde esta perspectiva, es, por ejemplo, la del borboteo del agua (equivalente al estremecimiento) que comienza insensiblemente a hervir en una cacerola, y que puede - si la fuente de calor se mantiene- dar paso a la ebullición propiamente dicha (la pasión) o regresar a una simple palpitación, casi imperceptible, si alejamos la cacerola de la fuente calorífica ${ }^{2}$.

Así, la especificidad del fenómeno de la emoción parece residir en este tipo singular de "mover", de "poner en movimiento". Las tres series etimológicas evocadas más arriba vienen a precisar, desde este punto de vista, el tipo de movilidad con el que nos enfrentamos en la emoción. Podemos decir que la serie de la facticidad suministra el punto de impulsión (lo que me adviene, me hace - a-fectar-) ${ }^{3}$, mientras que la serie de la pasividad (lo que yo sufro o soporto) traduce la disposición del sujeto que se encuentra propulsado fuera de sí mismo, es decir en situación receptiva. En cuanto a la serie referida al registro del sentir, ella precisa que este movimiento resulta de una articulación compleja de lo fisiológico (el cuerpo) y lo psíquico (el alma), de los que convendrá precisar su estatuto.

Es posible, entonces, deshacer el embrollo nocional inicial, aquel que encontramos en la mayor parte de documentos que no obstante se esfuerzan por lograr una delimitación de la emoción, empezando para ello por la especificidad del movimiento inherente a este fenómeno, para añadirle después, a título de rasgos que califican tal movimiento, las inflexiones de la afección, de la pathein y del sentir.

Además de este primer entramado de términos, encontramos igualmente en otras lenguas - notablemente en inglés y alemán-, otras nociones que vienen a aportar una nota suplementaria a la calificación de la emoción: es el caso

\footnotetext{
${ }^{2}$ El adjetivo "emocionante" [émouvant] refiere antes que nada a la dimensión sensible -e incluso sentimental- del fenómeno.

${ }^{3}$ En este contexto, la tematización heideggeriana de la Beweglichkeit -como auto-explicitación de la movilidad de la vida fáctica en los textos de la primera época, antes de la puesta en juego de la existencia y previo a la reflexión objetivante en sentido ingenuo- resulta del todo convergente a nivel estructural con la perspectiva aquí propuesta. Agradezco a Françoise Dastur por haberme indicado esta proximidad temática.
} 
de "mood"4, que corresponde al término a menudo adoptado para reflejar el alemán "Stimmung" ${ }^{5}$, traducido en francés, de modo un tanto insuficiente, por "humeur" o "disposition". Esta inflexión tiene por virtud la de insistir en la inscripción de la movilidad propia de la emoción en el contexto de la situación ambiente y atmosférica de su surgimiento, es decir, en su ligazón intrínseca con el mundo.

Otro término que viene a introducir una nueva connotación es "Gëmut", a veces mal traducido en inglés por "feeling"6 , y que da en francés "esprit" [espíritu], debido principalmente a la herencia kantiana. Este término significa la facultad global que cubre el conjunto de las cuatro facultades específicas del edificio crítico ${ }^{7}$. Sin embargo, es manifiesto que Gemüt, que reenvía a la raíz etimológica de Mut (valor), y encuentra sus derivados en la serie Gemütlichkeit, gemütlich (cordialidad, cordial, agradable) tiene su correspondencia precisa en el cor, cordis latino, esto es, en el corazón, a título de foco [foyer] de las emociones. Es por ello que el traductor inglés de la obra ya mencionada de Stephan Strasser no se equivocó al añadir al título Phenomenology of Feeling el subtítulo elocuente de Essay on the Phenomena of the Heart, como si él percibiese bien que "feeling" no traduce sino solo parcialmente el concepto de "Gemüt"8. Por otro lado, si interrogamos la raíz griega correspondiente, thumos, notablemente a partir de Platón ${ }^{9}$, descubrimos en qué medida el corazón es irreductible tanto a la sensibilidad puramente corporal (el epithymeticon) como al espíritu o la inteligencia (el nous). El thumos apunta a esa parte intermedia del alma que hace de reguladora de los deseos y que asiste al espíritu, como principio racional en la carnalización armoniosa de los mismos.

\footnotetext{
${ }^{4}$ Nam-In Lee, "Edmund Husserl's Phenomenology of Mood", en Natalie Depraz / Dan Zahavi (eds.), Alterity and Facticity. New Perspectives on Husserl, Dordrecht, Kluwer, 1998.

${ }^{5}$ La traducción de Stimmung por attunement (en inglés), si bien correponde literalmente al sentido del "acuerdo" presente en stimmen (to attune significa "acordar", "armonizar"), no da cuenta de la connotación atmosférica igualmente presente en el término, la que encontramos, por ejemplo, en su traducción corriente por "ambiente" ["ambiance"].

${ }^{6}$ Stephan Strasser, Das Gemüt, Utrecht, Uitgererij Het Spectrum, 1956; versión inglesa, Phenomenology of Feeling. An Essay in the Phenomena of the Heart, Pittsburgh, Duquesne University Press, 1977, trad. por Robert E. Wood.

7 Emmanuel Kant, Oeuvres complètes, Paris, Gallimard; et P.-E. Vignola, "'Seele' and 'Gemüt' bei Kant", actas del congreso de Ottawa consagrado a Kant, 1974.

${ }^{8}$ En este sentido también existen dificultades a la hora de traducir "emoción" en alemán. Erregung es el término más corriente, pero éste nos lleva sobre todo hacia la excitación, entendida en un sentido fisiológico; Erschütterung implica de entrada una fuerte emoción; aunque Gemüt sirve en general de compuesto (por ejemplo, por "emotividad", dado por el alemán "Gemütserregbarkeit"), su uso está lejos de ser dominante; rühen, que contiene en su significación una forma de movilidad, sería el más próximo al sentido primero de emocionar [emouvoir], como en sus sinónimos tocar [toucher, en el sentido de que algo me "toca", me "llega"] o enternecer [attendrir].

9 Platón, Timeo, 69a-70a-e; Fedro, 255a.
} 
Asociado a la razón, el corazón es ardor y coraje; ligado a los deseos, se hace amor o cólera. Pero, si el corazón permite precisar el nivel de acercamiento estructural de la emoción en el edificio psicológico de las diferentes facultades (en relación a la sensibilidad y al intelecto particularmente), es preciso decir todavía -y volveremos sobre ello- que él no permite describir una emoción singular en su fenomenalidad, puesto que el corazón se da como el foco o la sede de las emociones. En cualquier caso, Stimmung y Gemüt abren el estudio de la emoción hacia los planos de una ontología del mundo ambiente o de una psicología refinada de las facultades. La cuestión que se impone, desde ahora, es aquella que remite al campo de inscripción de la emoción o, de otro modo, al dominio conceptual en el cual podemos con derecho situar tal fenómeno.

\section{B. En el cruce de diferentes dominios}

Lo que en mayor medida impulsa a recorrer la literatura consagrada a esta cuestión es la determinación negativa recurrente de un campo de inscripción como éste. El fenómeno de la emoción es en efecto definido habitualmente como no revelando ningún dominio teórico, es decir, ningún plano gnoseológico o cognitivo. Es, por ejemplo, el caso -inaugural, desde el punto de vista fenomenológico- de la problemática husserliana, que toma como modelos los actos perceptivos y categoriales a título de actos privilegiados que dan acceso al conocimiento del objeto, y que hace uso de esos actos objetivantes como fundamento de actos no objetivantes, los cuales revelarían indistintamente el campo práctico, ético o estético ${ }^{10}$. Desde este punto de vista, las emociones, entendidas como Gefühle, lo son a título de actos no objetivantes fundados sobre actos objetivantes, primariamente perceptivos, y encuentran su inscripción de un modo indiferenciado y en un campo que solo podemos calificar negativamente como no teórico.

Si aceptamos, para empezar, la tripartición crítica kantiana, se plantea la cuestión de la situación de la emoción en el dominio práctico, es decir éticomoral, o bien en el dominio estético. Esta doble inscripción posible en la ética y/o en la estética corresponde, por ejemplo, a la elección de presentación de Algis Mickunas en su artículo consagrado a la emoción en la Encyclopedia of

${ }^{10} \mathrm{Cfr}$. sobre este punto los primeros parágrafos de Ideas I e Ideas II. 
Phenomenology ${ }^{11}$. Antes de examinar las diferentes concepciones de la emoción que podemos encontrar en las distintas fenomenologías -como las de Heidegger, Sartre o Ricoeur-, y también en psiquiatría y en psicología fenomenológica (en Erwin Straus y Frederic J. J. Buytendijk), el autor comienza su propuesta por esta bifurcación mayor entre ética y estética, que dirige en realidad la variación fenomenológica ulterior.

La idea según la cual las emociones están a priori enlazadas a una posición jerarquizada de valores encuentra en Max Scheler un representante eminente ${ }^{12}$. Para éste, los valores se dan a través de las diferentes polaridades emocionales, cuyo paradigma es el par amor/odio. Sin entrar en el detalle de la clasificación scheleriana, todas las polaridades de las emociones (alegría/tristeza; gusto/disgusto; placer/displacer) implican este doble proceso contrastado de valorización o de desvalorización. Es lo que conduce a Scheler a considerar que una ética, o al menos una axiología, se deja apercibir a través de cualquier manifestación emotiva. Paralelamente Moritz Geiger propondrá ${ }^{13}$, tan precozmente como Scheler, una fenomenología de las emociones inspirada por la consideración del campo estético. El placer (o el displacer) en la contemplación de un cuadro o en la audición de una pieza musical sirve de objeto a un análisis específico que implica un olvido de sí-mismo y una inmersión focalizada en el objeto. La experiencia estética ofrece por ello un hermoso ejemplo de descripción de las emociones.

Sin embargo, si la ética está originariamente implicada en el fenómeno de la emoción con motivo del proceso de evaluación que le subyace, y si la estética puede ofrecerle un punto de aplicación o un revelador decisivo, ninguno de estos dominios puede pretender agotar la descripción específica del fenómeno que tratamos de delimitar. La oposición teoría/práctica, que determina latu sensu esta inscripción bilateral de la emoción en la estética y en la ética, de inspiración kantiana $-y$ en el fondo muy husserliana-, encierra además una dificultad o, mejor dicho, una fragilidad interna. Pues con ella se ratifica la idea, contestable, según la cual la emoción no podría ser objeto de un conocimiento

${ }^{11}$ Algis Mickunas, "Emotion", en Lester Embree et al. (eds.), Encyclopedia of Phenomenology, Dordrecht / Boston / London, Kluwer Academia Publischers, 1997, pp. 171-177.

${ }^{12} \mathrm{Cfr}$. Zur Phänomenologie und Theorie der Sympathiegefühle und von Liebe und Haß (1913), y también Der Formalismus in der Ethik und die materialen Werteethik (1916).

${ }^{13}$ Moritz Geiger, "Beiträge zur Phänomenologie des ästhetischen Genusses", Jahrbuch für Philosophie und phänomenologische Forschung 1 (1913) 567-584. 
o de un saber en el que pudiese apreciarse su especificidad. Ahora bien, algunos trabajos contemporáneos, tanto en psicología como en psiquiatría, hacen causa común contra este prejuicio intentando dar cuenta del tipo singular de conocimiento del que sería depositaria la emoción ${ }^{14}$, lo que conduce a cuestionar firmemente la oposición excesiva entre lo cognitivo y lo afectivo ${ }^{15}$. Es entonces esta cuestión del conocimiento posible de nuestras emociones (en el doble sentido del genitivo: "cómo conocer mis emociones", pero también, "qué saber singular encierran las emociones mismas") la que me servirá aquí de hilo conductor en el estudio de los diferentes enfoques existentes que pueden dar un cierto acceso a la singularidad fenomenal de la emoción.

\section{II. ¿QUUE ENFOQUE PARA ACCEDER A LA EMOCIÓN EN SU SINGULARIDAD FENOMENAL?}

\section{A. El proceso clasificador}

El acceso más antiguo e igualmente más cómodo es de orden taxonómico. Casi contemporáneos de la gran clasificación de plantas de Tournefort y, más todavía, de los vivientes en el caso de Linneo ${ }^{16}$, los filósofos de la época clásica se emplearon -anticipándose medio siglo a sus colegas científicos- en definir las emociones y clasificarlas sistemáticamente, a saber, poniendo atención en el número, orden y relaciones de las mismas, de acuerdo a un juego casi constante de diferencias opositivas binarias.

Es el caso paradigmático del tratado de las pasiones de Descartes, titulado, concretamente, Les passions de l'âme (1645-1649), pero también, en una suerte de espejo crítico, del libro III de la Ética de Spinoza, "Del origen y de la naturaleza de las afecciones". Intereses taxonómicos o tipológicos paralelos, diremos, entre los científicos y entre los filósofos, y no necesariamente, por tanto, de influencia, puesto que, al menos en el caso de Descartes, resulta manifiesto que su clasificación de las seis pasiones principales, que son según él la admiración, el amor y el odio, el deseo, la alegría y la tristeza en el libro II del

\footnotetext{
${ }^{14}$ Cfr. Monique de Bonis, Connaître les émotions humaines, Liège, Mardaga, 1996; Daniel Goleman, L'inteligence émotionnelle, Paris, R. Laffont, 1997; y también Daniel Goleman (ed.), Healing Emotions. Conversations with the Dalaï-Lama on Mindfulness, Emotions and Health, Boston / London, Shambala, 1997.

${ }^{15}$ Cfr. Henri Grivois (ed.), Affectif et cognitif dans la psychose, Paris, Masson, 1993.

${ }^{16}$ Cfr. sobre este punto, Michel Foucault, Les mots et les choses, Paris, Gallimard, 1966, pp. 137s.
} 
Tratado, procede de una lectura crítica de la sistematización propuesta por Santo Tomás de Aquino en la Summa teológica (I-II, q. 24 aa. 2-4 a q. 48), la que a su vez quería servir de relevo sistemático y positivo a las consideraciones dispersas de Aristóteles en De anima, y a la axiología platónica de las partes del alma (concupiscible/irascible). Sin entrar en el detalle de tales clasificaciones sutiles y muy numerosas - pues encuentran continuación en Malebranche, en Leibniz, en los empiristas y también en el Kant de la Antropología-, y sin entrar tampoco en las críticas internas que cada filósofo lanza sobre los demás, pretendiendo detentar la llave criteriológica de la ordenación y jerarquía de las pasiones, lo que resulta de todas estas tentativas de tipología es su carácter abstracto. Estas taxonomías, pese a ser muy sofisticadas y a estar muy refinadas terminológicamente, permanecen sin embargo poco justificadas, pues subyace en ellas la tesis que descansa, en último término, en la distinción más que discutible entre pasiones primitivas y pasiones derivadas ${ }^{17}$.

En el fondo, podemos formular fácilmente tres grandes objeciones a esta metodología de identificación de las emociones por su clasificación taxonomista:

1) El criterio de determinación del orden de las pasiones parece poco fundado. ¿Por qué la admiración habría de ser la primera de las pasiones (Descartes)? El hecho de que la admiración encierra sorpresa y asombro [surprise et étonnement] frente a lo desconocido, y el hecho de que no implica - a diferencia del amor o del odio- una polarización del bien y del mal, no permite de ningún modo concederle el decreto de más primitiva.

2) El acento puesto sobre las "pasiones" (Descartes) o las "afecciones" (Spinoza), es decir, sobre las emociones fuertes, permite identificarlas con mayor facilidad. Pero, si Descartes, por ejemplo, concibe específicamente las "emociones" como movimientos del espíritu que provocan en la sangre las pasiones del alma, sin tener ésta desde esta perspectiva imperio alguno sobre los movimientos orgánicos, su insistencia puesta en el padecimiento del alma deja en sombra las tonalidades afectivas más imperceptibles, las menos violentas, las cuales no serían menos atribuibles a la relación de lo físico y lo psíquico y, por tanto, no deberían reducirse al mero cuerpo orgánico. En definitiva, al inte-

${ }^{17}$ Henri Parret, Les Passions. Essai sur la mise en discours de la subjectivité, Liège, Mardaga, 1986. 
resarse por las pasiones-shock, Descartes deja de lado la existencia de estas tonalidades más insensibles, como si solo las emociones fuertes importasen.

3) La estructuración en pares de opuestos (amor/odio; alegría/tristeza) destaca la idea de un salto, de una discontinuidad entre pasiones. De ello resulta que el movimiento de transición de una a otra, el movimiento de aparición gradual o de surgimiento brusco, y, en definitiva, la dinámica inmanente a cada pasión, permanece como un punto ciego de tales análisis. Con ello se persevera en la idea de que cada pasión es una realidad estable, cerrada, definida de una vez por todas, y de la cual podemos aprehender sin dificultad su esencia o naturaleza intangible ${ }^{18}$.

Desde este punto de vista taxonomista, podemos decir que una buena parte de la psicología del siglo XIX, e incluso del siglo XX, hereda este modelo de acercamiento metodológico, al modo de un lastre, y recayendo con ello en los mismos problemas y las mismas objeciones ${ }^{19}$.

\section{B. El acercamiento científico de tipo psico-fisiológico lato sensu}

Pero también podemos, de manera más interesante, distinguir a partir de aquí tres tipos de actitudes científicas que han propuesto criterios bien distintos a la hora de acceder a la emoción. Bajo el prisma científico, estos criterios no son necesariamente exclusivos: en el mejor de los casos, ellos pueden incluso revelarse como complementarios. Precisemos antes de nada que el orden en el que serán presentados aquí corresponde al grado de su pertinencia fenomenológica.

1. Identificación de la emoción por su objetivación corporal, es decir, en este caso, muscular o neuro-vegetativa.

El planteamiento pasa por explicar la emoción a partir de la presencia de reacciones fisiológicas cuantificables: hipertonicidad motriz, aceleración cardia-

\footnotetext{
${ }^{18}$ Notemos que esta objeción nos devuelve al cuadro fijista en el cual se elaboran paralelamente las taxonomías científicas. Desde esta perspectiva, Leibniz abre otra vía, en la cual -y por más embrionaria que ésta sea- la dinámica combina continuidad, transiciones y descripción del advenimiento de pequeñas percepciones insensibles (Cfr. sobre este tema los Nouveaux essais sur l'entendement humain).

${ }^{19}$ De acuerdo con Paul Fraisse ("Les émotions", en Paul Fraisse / Jean Piaget (eds.), Traité de psychologie expérimentale, t. V, $1975^{3}$ ), el problema de la distinción de las emociones (primarias, mixtas) es muy complejo. Darwin distingue siete grupos de emociones, Cattell 10 por análisis factoriales (1957), Izard (1971) y Pluchick (1980) hablan de 8, Watson (1927), refiriéndose solo al niño, distingue 3 (miedo, amor, cólera).
} 
ca, aumento de la presión sanguínea, descarga de adrenalina, modificaciones del electroencefalograma, etc.

Pero estas reacciones pueden observarse en otras conductas, lo que significa que no son intrínsecamente características de la emoción. Podemos ahora, de un modo más preciso, interesarnos por los centros nerviosos específicos de la emoción, y fijar el rol que juega el sistema límbico o tímico, como título del conjunto de las estructuras corticales ${ }^{20}$.

En este contexto, los datos neuro-fisiológicos sirven de soporte a la validación del acceso a la emoción. En una quasi-inversión de la tesis cartesiana, el cuerpo, en último término, parecería ser la causa cuyo efecto psíquico sería la emoción. Se sustituye de este modo un mecanismo causal espiritualista (el alma es el principio causal por la voluntad libre de los movimientos del cuerpo, sobre el cual ella posee todo el imperio - tesis criticada desde temprano por Spinoza-) por un mecanismo causal inverso, de tipo materialista. Es lo que hoy en día se denomina, en las ciencias cognitivas, un reduccionismo primario, del cual Changeux nos da una imagen caricaturesca; es lo que Husserl, desde bien temprano, critica bajo el nombre de naturalismo científico, con el argumento fuerte de que no se puede explicar lo superior por lo inferior.

Esta primera actitud pone de relieve un positivismo experimental. El criterio de acceso a la validez, es decir, a la verdad de la emoción, proviene en este caso de los resultados que ofrecen los exámenes basados en la cuantificación, y también de los parámetros que revelan los datos neuro-fisiológicos.

\section{Acceso a la emoción desde su expresión corporal}

El criterio de acceso ya no es, aquí, la validación de los datos neurofisiológicos, sino la expresividad emocional, bien sea en el lenguaje, en la gestualidad o en el comportamiento. En este plano se ha podido definir la emoción como un problema de adaptación de la conducta o del comportamiento o, también, como una ruptura del comportamiento habitual frente a ciertas situaciones o ante tareas muy difíciles de resolver, especialmente frente a la novedad de un caso que desencadena algún tipo de sorpresa. Janet, uno de los psicólo-

${ }^{20}$ Cfr., por ejemplo, el artículo de Francisco J. Varela titulado "The Body's Self" (en Daniel Goleman (ed.), Healing Emotions. Conversations with the Dalaï-Lama on Mindfulness, Emotions and Health, op. cit.), el cual se propone mostrar la pertinencia de una epistemología inmunológica de la auto-regulación interna del sistema tímico, con la consiguiente crítica de una epistemología anterior centrada en la noción de reactividad externa. 
gos que sirve de cantera de conocimientos científicos a Sartre ${ }^{21}$, afirma en este sentido que "la gran causa de la emoción es la sorpresa". A la inversa, una excesiva preparación conduce a menudo a una emoción que los actores gustan de llamar "miedo escénico" ("le trac").

Pero la expresividad corporal juega igualmente el papel de interfaz en la manifestación de la emoción, siendo el rostro su expresión primera. Si me sonrojo o me ruborizo, por ejemplo, esto significa que me siento intimidada al tener que hablar delante de un auditorio muy numeroso. Si en clase me tiembla la voz, esto significa que me siento desestabilizada por la actitud de un alumno. Si no encuentro las palabras justas delante de alguien, quizá sea porque esa persona me impresiona. Si en cambio palidezco, es porque la persona con quien hablo me acaba de anunciar una noticia terrible.

Pero la dificultad de un criterio expresivo como éste es que no resulta uní$v_{0 c 0^{22}}$. Yo puedo, en otras condiciones, sonrojarme porque acabo de decir algo que me devuelve a un momento anterior de discusión. Me puede temblar la voz en clase porque estaba distraída, pensando, por ejemplo, en lo que tengo que hacer más tarde. Puede que tenga una palabra en la punta de la lengua, y que ésa sea la razón de que me quede callada, buscándola; puede también que palidezca de cólera al escuchar la noticia, pues hubiese preferido que fuese otra persona quien me la diese.

Por tales motivos, este criterio no permite fijar con exactitud la emoción en cuestión. La expresión pone de relieve la apariencia (Schein) de la que habla Heidegger en el $\S 7$ de Sein und Zeit, como "se montrer-autrement qu'il n'est", como síntoma equívoco de una vivencia interna inaccesible y en todo caso no identificable según este criterio. En este sentido, tanto la objetivación neurofisiológica como la sintomatología expresiva siguen siendo criterios externos que no permiten acceder a la singularidad fenomenal de la emoción.

3. Acceso a la emoción por la experiencia subjetiva de aquel que está emocionado [ému]

Será entonces a partir de un criterio intuitivo de orden subjetivo que vamos a acceder verdaderamente a la emoción. Esta validación interna es una auto-

\footnotetext{
${ }^{21}$ Cfr. Jean-Paul Sartre, Esquisse d'une théorie des émotions, Paris, Hermann, 1995, pp. 23s (Cfr. de Pierre Janet, por ejemplo, L'obsession et la psychasthénie, citado por Sartre).

${ }_{22} \mathrm{Cfr}$. Monique de Bonis, op. cit.; Paul Fraisse, op. cit.
} 
validación, la que hace que solo aquel o aquella que siente [ressent] efectivamente una emoción pueda hablar de ella de manera justa y auténtica. Todos los índices externos, desde este punto de vista, no serán sino confirmaciones eventuales de un primer acceso determinante, que es el de la vivencia de aquel o aquella que hace la experiencia de una emoción singular.

Ésta es la posición que William James reivindicó, tempranamente, al defender la idea de que la emoción es, en realidad, la conciencia que yo tengo de las turbaciones suscitadas en mi cuerpo por una tal emoción ${ }^{23}$. Ahora bien, una tesis como ésta, que sitúa en primer lugar el primado y la validación de la vivencia de la primera persona, sufre el descrédito que la crítica filosófica sitúa bajo el término de subjetivismo, y no menos el de la crítica científica bajo el epíteto condenable de introspección, sinónimo de romanticismo y de irracionalismo.

Desde un punto de vista científico, una respuesta meditada consistirá en afirmar que conviene desplegar conjuntamente, de manera concertada, estos tres criterios: el objetivo, según la validación explicativa, el intersubjetivo, a través de la expresividad, y el subjetivo, a partir de la intuición de la vivencia interna. Desde un punto de vista filosófico, la validación, al ser por principio de tipo categorial, desarrollará las herramientas de categorización que confieren a la vivencia intuitiva interna un estatuto de objetividad $y$, en consecuencia, de universalidad: aprovechando la fuerza intuitiva que se pone en juego en la vivencia interna de un sujeto se logra asegurar la objetividad del fenómeno a describir en base a su categorización, poniendo con ello a distancia los criterios de acceso en los cuales la objetivación permanece en todo momento externa (datos neuro-fisiológicos y expresiones de todo tipo). Es esto precisamente lo que trata de hacer la fenomenología, aquí en particular, para acceder a la emoción como fenómeno singular.

\section{LAS EXPERIENCIAS FENOMENOLÓGICAS DE LA EMOCIÓN}

\section{A. La intencionalidad: Gefühl, Stimmung y Trieb}

Desde esta perspectiva, la primera herramienta que pone en marcha la fenomenología para acceder a la emoción es la estructura intencional del apare-

${ }^{23}$ Cfr. William James, "What is an Emotion?", Mind 9 (1884) 188-205. 
cer, que cortocircuita tanto la exterioridad del síntoma aparente como la interioridad inaccesible de la vivencia subjetiva privada.

1. El problema de la distinción entre sentimiento (Gefühl) y emoción: la referencia al objeto sentido [ressenti] ${ }^{24}$ y el modelo de la intencionalidad perceptiva objetivante.

¿Cuál es la aprehensión husserliana de las emociones, entendida desde su estructuración intencional? El fundador de la fenomenología suele referirse a las emociones en términos de Gefühle (sentimientos, feelings), al menos en la época de las Investigaciones lógicas, en la que encontramos formalizada la intencionalidad. No es entonces seguro - hay que tenerlo rápidamente en cuenta- que las referencias de Husserl nos permitan acceder verdaderamente a la emoción en toda su concreción, pues es posible que él no capte sino una dimensión unilateral del fenómeno.

Desde las Investigaciones lógicas y, en particular, en la quinta, en la que se desarrolla con mucho acierto el análisis intencional de la conciencia, Husserl define la intencionalidad como aquella estructura de la conciencia que permite la correlación entre una vivencia inmanente y el objeto vivido por el acto que aprehende y formaliza la materialidad de tal vivencia. La experiencia es intencional si ella remite a un objeto en el modo de la vivencia, es decir, como vivido por ella; la experiencia no será intencional si ella no refiere a ningún objeto. Ahora bien, en alemán disponemos de dos términos para calificar estos dos tipos de experiencias: Erfahrung; Erlebnis. Estas dos experiencias están entrelazadas entre ellas de modo que la experiencia, en tanto vivencia, suministra la base (hylética) como condición material de posibilidad de la experiencia intencional. Las Erlebnisse son, por tanto, la piedra angular de los actos, sin ser ellas mismas los actos en sí. Tales vivencias son primeramente determinadas como Empfindungsdata, como sensaciones o datos sensibles que forman el contenido material del acto primeramente perceptivo. En principio, la sensación vivida no tiene relación con un objeto, esto es, dicho de modo general, con algo vivido

\footnotetext{
${ }^{24}$ La lengua española utiliza el verbo "sentir" tanto para sensaciones como para sentimientos. Decimos, por ejemplo, "sentir frío" y "sentir rabia". El francés diferencia estas dos acepciones con los verbos "sentir" (para sensaciones) y "ressentir" (para sentimientos o emociones). Hay que notar, sin embargo, que esta diferencia no es siempre unívoca -en algunos casos puede utilizarse el verbo "sentir" para sentimientos y el verbo "ressentir" para sensaciones-, lo que no debe conducirnos a testimoniar una imprecisión de la lengua francesa, sino, más bien, a atestiguar lo estrechamente ligadas que pueden llegar a estar estas dos dimensiones del ser humano [N. del T.]
} 
como objetivo, y puede entonces concebirse con justicia a nivel experiencial como autónoma en relación a la determinación intencional del acto, el cual permanece, en sí mismo, subordinado en tanto que necesita de su substrato sensible.

A la luz de este análisis se plantea ahora la cuestión del estatuto intencional o no- de los Gefühle ( $L U 1,576)$. Una lectura atenta de la quinta investigación lógica nos revela la posición equívoca de Husserl sobre este punto. Al lado de las afirmaciones que sugieren el carácter intencional del sentimiento ( $L U 1,569$ : estamos reconfortados por una melodía, sobresaltados por un sonido violento), Husserl insiste en la dimensión no intrínsecamente intencional del sentimiento: considerados en sí mismos, los Gefühle son puros estados psíquicos (psychishe Zustände) que reciben de su presentación (Darstellung), y solo de ella, la forma de su dimensión intencional ( $L U 1,570)$. En realidad, esta ambivalencia requiere una distinción entre dos formas de intencionalidad, objetivante una (que presenta la materia sensible en una forma que se despliega de manera trascendental más allá de la materia), no objetivante la otra (que concierne a una intencionalidad inmanente puramente sentida y que permanece por tanto en sí misma). Estas dos intencionalidades corresponden al sentimiento como acto y al sentimiento como pura sensación inmanente (LU1, 574). Ahora bien, la cuestión que se plantea a continuación es la de la autonomía posible de la sensación inmanente en relación al acto intencional. La tesis más conocida de Husserl, al menos en la época de las Investigaciones lógicas, descansa en efecto en la relación de fundamento de la dimensión no objetivante sobre la objetivante, lo que viene a otorgar un primado del acto sobre la vivencia inmanente; acto en tanto que vive una propiedad objetiva inseparable de la excitación emocional inmanente (LU1, 574).

2. El problema de la distinción entre emoción y Stimmung, y la referencia al mundo sentido [ressenti] como modelo de una intencionalidad no objetivante.

Más tarde, en los manuscritos del grupo M (1900-1914), Husserl introducirá la noción de Stimmung ${ }^{25}$. Ahora bien, será precisamente una tesis como la anunciada, característica de la fenomenología estática y basada en la funda-

${ }^{25}$ Cfr. Ms. MIII 3 II1 (1900-1914), titulado: "Estudios sobre la estructura de la conciencia". Nosotros nos hemos basado sobre este punto en Nam-In Lee, op. cit. 
mentación de la dimensión no objetivante sobre la objetivante, la que en los textos ulteriores sobre la Stimmung Husserl se empleará en relativizar.

No obstante, un primer índice de la autonomización posible de la vivencia emocional con respecto a la intencionalidad de acto que se dirige a un objeto puede encontrarse ya en este pasaje de la quinta investigación: "Las sensaciones de placer y de dolor pueden perdurar, mientras que desaparecen los caracteres de acto edificados sobre ellas. Cuando los hechos suscitadores del placer han pasado a segundo término, cuando ya no son apercibidos afectivamente, e incluso quizá ya no son objetos intencionales, la excitación placentera puede durar todavía largo tiempo; y eventualmente es sentida como agradable" ${ }^{26}$. Habría entonces autonomía posible, que no sería sino un instante de la experiencia, de la intencionalidad emocional no objetivante.

Husserl profundizará en este punto en los manuscritos mencionados, definiendo la Stimmung como una mezcla de sentimientos variados al interior de un flujo de conciencia ( $M, 90,99)$ o, también, como el oscuro plano de fondo (dunkler Hintergrund) de tales sentimientos ( $M, 95)$, como horizonte latente de su coexistencia intrincada. En tanto que segundo plano o plano de fondo de esta particular suerte de horizonte, la Stimmung mantiene una relación distanciada, indirecta, con los objetos dados, lo que conduce a Husserl a hablar a tal propósito de "intencionalidad oscura" (M, 95): "La Stimmung es la unidad de los sentimientos qui confiere a cada vivencia que aparece un color, un color unificante, un buen brillo, una coloración hundida en tristeza" ( $M, 30)$.

La noción de Stimmung, llamando al aspecto atmosférico de una emoción o al sentimiento global de ambiente, contribuye claramente a des-objetivar, a des-focalizar o des-localizar la vivencia emocional de su subordinación a un objeto que la motiva. La Stimmung haría aparecer el objeto no tanto como un contenido material determinado sino como el color mismo de los acontecimientos y de las situaciones ${ }^{27}$, dotándola del mismo modo de un estatuto de difusividad $^{28}$, de suave impregnación.

\footnotetext{
${ }^{26}$ Edmund Husserl, Investigaciones lógicas, 2, Madrid, Alianza Editorial, 1982, p. 510. La versión francesa aportada por Depraz en el texto original es ésta: "Des sensations de plaisir ou de douleur peuvent perdurer quoique les actes fondés sur eux passent à l'arrière-plan et s'évanouissent. Lorsque les faits qui provoquent le plaisir s'évanouissent en passant à I'arrière-plan, ne son plus aperçus comme colorés émotionnellement et cessent même tout à fait d'être des objets intentionnels, l'excitation plaisante peut fort bien perdurer un moment; elle peut elle-même être ressentie comme source d'agrément" (LU1, 574s). [N. del T.].

${ }^{27}$ En esta línea, la intuición de Eugene Gendlin, "A Phenomenology of Emotions. Anger", en David Carr / Edward S. Casey (eds.), Explorations in Phenomenology, The Hague, M. Nijhoff, 1973, pp. 367-
} 
3. El problema de la articulación entre Trieb y emoción y la referencia a la intencionalidad genética de tipo pulsional: el estatuto del Leib y de las kinestésias.

Al mismo tiempo que la vivencia emocional - al pasar de su definición como Gefühl a su aprehensión como Stimmung - se des-focaliza, abriéndose al ambiente de un horizonte de mundo y pasando con ello de una intencionalidad objetivante a una intencionalidad no objetivante, la emergencia de un nuevo tema, la pulsión, nos lleva del plano estático a la dimensión genética, aquella que pone el acento sobre el enraizamiento y acontecimiento de la emoción. Tratándose de un objeto determinado -como pasa en el caso del Gefühl, el cual asigna un motivo local y objetivante a la emoción-, la emoción como Stimmung procede como un simple ensanchamiento difusivo que no sobrepasa el ámbito estático. Solo el Trieb permite aparecer y describir la dinámica misma de la producción de la emoción. Dicho esto, y más allá de la distinción entre una emoción localizada y una emotividad difusiva, será el modo mismo de engendramiento de la emoción el que será aquí tematizado.

En los años 30 aparece la noción de pulsión (Trieb) ${ }^{29}$ para designar la fuente genética de la emoción, al lado de otros términos con mayores connotaciones empíricas como aquellos de instinto (Instinkt) o deseo (Begierde). Sin embargo, bien se trate de ensanchar de modo estático el objeto de la emoción en dirección de su apertura al mundo con la noción de Stimmung, bien de profundizar del lado genético poniendo al día su génesis con la noción de Trieb, el cuadro conceptual dado por la intencionalidad permanece determinante de punta a punta. Lejos de desbordarse o de disolverse en otro concepto (el de trascendencia, en Heidegger, o el de carne del mundo, en Merleu-Ponty), es la noción misma de intencionalidad la que se encuentra profundizada y enriquecida a la luz de las modificaciones radicales que hemos tratado. El cuadro intencional, aun habiéndose "genetizado" con el concepto de pulsión, no por ello se ha abandonado. Antes bien se profundiza, y viene atravesado por un replantea-

398, que tematiza un feltsinn irreductible al Körper y no menos al Leib, dotado de una intencionalidad no objetivante donde la tonalidad (teneur) emocional es más situacional que puntual, encuentra aquí un punto de impulso fecundo.

${ }^{28}$ A propósito de esta noción de "difusividad", cfr. Natalie Depraz, Lucidité du corps. De l'empirisme trascendental en phénomenologie, Dordrecht, Kluwer Academic Publishers, 2001, capítulo 1.

${ }^{29} \mathrm{Cfr}$. Ms. A VI 26 (1921-31); Ms. A VI 34 (1931). Cfr. también Nam-In Lee, Edmund Husserls Phänomenologie der Instinkte, Dordrecht, Kluwer, 1993. 
miento del primado del acto objetivante, lo que conlleva, por otra parte, la autonomía posible de la sensación intencional no objetivante.

Será por ello que Husserl, a la sazón y para calificar esta intencionalidad pulsional, hablará de intencionalidad oscura, latente o pasiva, expresiones bien cercanas a aquellas que trataban, ya en los años 20, de dar cuenta de la Stimmung. La "genetización" de la emoción por la puesta al día de la fuente pulsional tiene entonces como característica la de poner en primer plano el enraizamiento corporal-carnal, de tipo kinestésico, de la vivencia intencional. Es esta articulación entre Leib y emoción la que conviene ahora precisar.

Desde esta perspectiva, conviene antes de nada distinguir entre kinestesia estática y kinestesia genética. La primera responde a una sensación localizada y localizante, descrita de modo ejemplar en Ding und Raum (1907), y situada sobre un plano constitutivo homólogo al del análisis intencional de los sentimientos; la segunda se libera de la condición objetivante de la sensación para desplegarse en el modo de una forma de movilidad sensorial abierta. En otros términos, la intención kinestésica que finaliza en el objeto apuntado, voluntario, se libera del "in" para volverse tensión interna, a saber, en términos husserlianos, "deseo" (Begierde), o también "tendencia, aspiración" (Streben) ${ }^{30}$. En este caso es la génesis dinámica de la sensación, en su movilidad inmanente, lo que funciona como objeto de la descripción, y no el movimiento sensible dado a la conciencia en su localización orgánica. La cuestión que habrá que responder puede, en consecuencia, formularse de la siguiente manera: toda sensación vivida, sentida [ressentie], ¿es ella "localizante" -ésta es la tesis de Husserl en 1907-, o hay un modo de sentir que escapa a una tal localización focalizante para abrirse sobre una modalidad más difusiva de la espacialización sensorial? Es este doble postulado el que conviene poner a prueba articulando para ello la motricidad corporal y la movilidad emocional.

Ahora bien, un análisis tripartito de la emoción de este tipo, organizado de modo trascendente sobre los parámetros del objeto (1), del mundo (2) y de la inmanencia de la pulsión corporal (3), encuentra en Sartre, en Buytendijk y en Merleau-Ponty, tres filiaciones contrastadas. Los dos primeros retoman a su manera el cuadro intencional de la emoción, bien para refutar la tesis de la

\footnotetext{
${ }^{30}$ Hua XV, Beil. XIX (sin duda de septiembre de 1931), titulado "Kinesthèse en tant que tension du désir et chemin de la volonté".
} 
emoción como estado psíquico inmanente y avanzar en su lugar la tesis de la emoción en tanto conducta inscrita en el mundo (Sartre en Esquisse d'une théorie des emotions, con apoyo en la psicología de la emoción como conducta típica de Janet); bien para proponer una diferencia entre sentimiento y emoción que pase por el carácter intencional de uno y el carácter no intencional y no objetivante del otro (Buytendijk en The Phenomenology of Feelings and Emotions). Sobre la base de una confusión perjudicial de estas dos nociones (sentimiento / emoción) se perfila sin embargo y de a poco el embrión de otra distinción: la sensación, como excitación o irritación emotiva, no es objetivante, al tiempo que el sentimiento como acto sí lo es. Aquí Buytendijk retoma y precisa el encuadre husserliano distinguiendo estas dos nociones -cosa que Husserl, por su parte, no había hecho con suficiente claridad-, identificando no obstante intencionalidad y objetivación - cosa que Husserl, al contrario, había tratado de diferenciar. Merleau-Ponty, por último, en La phénoménologie de la perception, enraíza deliberadamente la emoción en el cuerpo, hasta el punto de absorber aquélla en la motricidad corporal, es decir, de confundir e"mocionalidad" y motricidad corporal. Ahora bien, si la emoción destaca una forma de movilidad, no por ello el cuerpo y su motricidad kinestésica son identificadas con aquélla, la cual no se agotaría, en todo caso, en una descripción de tipo motriz.

¿Quiere esto decir que la solución propiamente husserliana, que consiste en ver en la pulsión la fuente genética de la emoción, es la más satisfactoria? ¿Toda emoción encuentra su fuente en el impulso de un deseo? Y si esto es así, ¿puede decirse que una comprensión de este tipo permite por ello la descripción de la singularidad fenomenal de la emergencia de la emoción? Para poner a prueba esta última tesis, esto es, para describir con más precisión la movilidad singular de la emoción, es conveniente en este momento 1) concentrarse sobre su modo de temporalidad; 2) precisar su articulación con la corporalidad pulsional y kinestésica, especificando estos dos modos de movimiento -movilidad / motricidad-y su mutua relación; 3) definir el modo singular de centración de las emociones, y, por último, 4) describir la génesis emergente de la vivencia emocional desde su centro orgánico específico. 
B. El modo de temporalización de la emoción: de la distinción entre emoción y afección.

Aunque cada vivencia emocional es siempre una vivencia singular, no es nunca una vivencia puntual: la vivencia se inscribe en un ambiente, que es el del mundo en torno, y se difumina entre los objetos. La vivencia echa raíces, teniendo su fuente en una profunda inmanencia, en una pulsión del orden del deseo que logra inscribirse orgánicamente en el cuerpo.

Con una mayor precisión, si la vivencia no es puntual es porque se sitúa en un flujo de vivencias al que corresponde un horizonte inmanente de despliegue [déploiement]. Es este horizonte inmanente y fluyente, indisociable de la emoción singular que emana de él, el que quisiera ahora tomar como hilo conductor, y ello, haciéndole justicia bajo dos ángulos tomados poco en cuenta -o cuanto menos disociados- en los análisis fenomenológicos: 1) la temporalidad de la emoción, es decir el modo de temporalización que le es propio; 2) la estructura unificada de la movilidad fluyente como tal.

Los fenomenólogos que han puesto en relación temporalidad y afección (principalmente Heidegger y Merleau-Ponty) lo han hecho para insistir en el rol constitutivo del tiempo, volviendo sobre la afección para analizar su modo específico -derivado- de temporalización ${ }^{31}$. En ningún momento proponen una distinción cuidadosa entre afección y emoción, ni a fortiori un análisis del modo singular de temporalización de la emoción. Si Merleau-Ponty, a diferencia de Heidegger, menciona la experiencia emotiva o emocional, será, como hemos visto, para vincularla exclusivamente a la motricidad kinestética en la que él la sumerge. De este modo, la distinción que Merleau-Ponty elabora, entre afección y emoción, pasa por la oposición entre tiempo y espacio, como si la afección tuviese que ser exclusivamente vinculada al tiempo y la emoción al espacio; como si, en consecuencia, no quedara ya lugar para una temporalidad emocional específica (ni por otro lado para una espacialidad afectiva).

Ahora bien, aquello que nosotros queremos confirmar, es que hay una temporalidad propia de las emociones, que Kant bien pronto había captado de manera clarividente, si bien distinguiendo esta temporalidad de la temporalidad de la pasión. El autor de la Anthropologie du point de vue pragmatique describe

${ }^{31}$ Cfr. sobre este punto, Natalie Depraz, "Can I Anticipate Myself? Temporality and Self-affection", en Dan Zahavi (ed.), Self-awareness, Temporality and Alterity. Central Topics in Phenomenology, Dordrecht, Kluwer, 1998. 
la emoción bajo el signo de "la precipitación", de "la memoria corta", del "ataque de apoplexia"; la pasión como "llevando su tiempo" ["prenant son temps"], reflexionando para alcanzar su objetivo ${ }^{32}$. El mérito de Kant consiste en atribuir un modo de temporalidad propio a la emoción; su defecto consiste en analizarla en términos de precipitación -es decir, de instantaneidad-, como si toda emoción fuese una emoción fuerte, asimilando con ello, como veremos, la emoción al afecto. En lo que respecta a esta reconducción, ésta resulta claramente dependiente del cuadro cartesiano, el cual atiende exclusivamente a las emociones fuertes.

Pero, si decidimos tomar en consideración nuestro régimen emocional en lo que respecta a su fluctuación incesante y más insensible, dejando de lado las manifestaciones emocionales más "chillonas" ["criantes"] (los afectos / afecciones), nos damos cuenta que en tal caso emerge una temporalidad mucho más lábil y frágil. Las tonalidades emocionales que no dejan de habitarnos y que nos atraviesan a cada instante solicitan sin duda un esfuerzo de atención específico -e incluso inhabitual- para ser percibidas y/o apercibidas (quizás una suerte de reducción, de descentramiento en relación a nuestra actitud natural absorbida en el mundo y poco atenta a sí misma ${ }^{33}$ ), puesto que ellas son extremamente fluctuantes. Su modo de donación, distinto, requiere entonces un análisis específico.

Es gracias a ello que comprendemos que Heidegger $-y$ algunos de sus herederos más eminentes ${ }^{34}$ - se haya centrado en esta cuestión de los afectos, de las tonalidades afectivas, describiéndolas sobre la base de un análisis de la temporalidad del acontecimiento (Ereignis). La angustia, de modo ejemplar, pero también el dolor y la violencia que los prisioneros de Platón enfrentan en

32 Emmanuel Kant, Anthropologie du point de vue pragmatique, Paris, Vrin, 1984, Libro III, trad. por Michel Foucault, "De la faculté de désirer": § 74, "Des émotions dans leur opposition avec la passion", p. 109: "Ce que l'emotion de la colère ne fait pas dans sa précipitation, elle ne le fera jamais; elle a la mémoire courte. La passion de la haine au contraire prend son temps pour s'enraciner profondément et penser à l'adversaire". Cfr. también François Marty, "Raison pure, raison affectée. A propos de l'affectivité chez Kant", Epokhè 2 (1991) 9-33.

${ }^{33}$ Es el propósito del libro de Natalie Depraz / Francisco Varela / Pierre Vermersch, On Becoming Aware: The Pragmatics of Experiencing, Amsterdam, Benjamins Press, 2003, que describe metódicamente este movimiento reductivo de presencia atentiva por la que accedemos a una zona preconsciente de nosotros mismos.

${ }^{34}$ Martin Heidegger, Sein und Zeit, Tübingen, Niemeyer Verlag, 1984. Versión francesa: Paris, Authentica, 1985, § 29, § 40, § 68b, trad. fr. de Emmanuel Martineau; Eugen Fink, "Que veut la phénoménologie d'Edmund Husserl?" (1934), en Studien zur Phänomenologie (1930-39), Den Haag, M. Nijhoff, 1966, "Que veut la phénoménologie d'Edmund Husserl?" (1934), 1. L'idée de fondation; Emmanuel Lévinas, Autrement qu'être ou au-delà de l'essence, Den Haag, M. Nijhoff, 1974; Jean-Luc Marion, Etant donné. Essai d'une phénoménologie de la donation, Paris, P.U.F., 1997, § 16 ("L'incident") et § 17 ("L'événement"). 
las sombras de la caverna, y que dibujan para Fink la "catástrofe" que significa la reducción, en tanto ruptura brutal de la actitud natural; el traumatismo patético levinasiano de la exposición inmemorial al otro, que hace de mí su rehén originario, o también la sorpresa que suscita el acontecimiento, por definición irrepetible y que excede todo análisis (Jean Luc Marion), se dan en efecto en un tiempo-relámpago [temps-éclair], que es el de lo fulgurante [fulgurance]. Con toda seguridad, éstos hacen en este sentido [el] "acontecimiento" ["événement"]. Pero estos son afectos que aparecen mejor bajo la mirada a consecuencia de aquella intensidad y paroxismo suyos. Se destacan de este modo netamente del fondo emocional permanente en el que estamos sumergidos $y$ que permanece como tal in-interrogado ${ }^{35}$. En el fondo, describir las tonalidades afectivas que se nos imponen brutal y violentamente, en lugar de aquellas otras tonalidades emocionales que nos atraviesan de modo incesante sin que nosotros las destaquemos como tales, conlleva el seguir inscritos en el cuadro cartesiano de la descripción de las pasiones, que son un objeto cómodo de atención y de tematización, en tanto que sobrepasan necesariamente un determinado umbral de intensidad, señalándose a sí mismas y distanciándose en cierto modo de nosotros. Aquí quisiéramos, al contrario, poner el acento en la herencia, más leibniziana, de las pequeñas tonalidades emocionales insensibles, desplegando el tipo de temporalidad que les es específica.

Si "tonalidades afectivas" y "tonalidades emocionales" están caracterizadas por su in-intencionalidad pasiva, en el sentido de que me son dadas, de que se me imponen sin que yo sea su origen ${ }^{36}$, el afecto se da como una afección repentina, inesperada e instantánea, mientras que la emoción supone una cualidad de duración y de persistencia más inaprensible. Esta fluctuación, lenta e insensible, de nuestro régimen emocional, más difícil de ceñir debido a que no cesa jamás, puede ciertamente llegar a cristalizarse en ciertos momentos, precisada en un afecto que hace irrupción y atraviesa el umbral de intensidad que lo destaca -lo que convierte tales momentos en "acontecimientos"-, pero esto no implica que nuestra vida emocional se agote con ello.

\footnotetext{
${ }^{35} \mathrm{Cfr}$. sobre este punto, Natalie Depraz, "Das Ethos der Reduktion als leibliche Einstellung", en Bernhard Waldenfels (ed.), Perspektiven phänomenologischer Ethik, Münschen, Fink Verlag, 1997.

${ }^{36}$ Cfr. sobre este punto François Dastur, "Pour une phénoménologie de l'événement: I'attente et la surprise", Etudes phénoménologiques 25 (1997), pp. 64s.
} 
La temporalidad lábil de este flujo multiforme y cambiante puede ser objeto de una atención específica, revelándose además su diferencia respecto de la temporalidad aconteciente [événementiale] y fulgurante de los afectos ${ }^{37}$. Glen Mazis, por ejemplo, pese a no distinguir terminológicamente entre afección y emoción, describe muy finamente este flujo y reflujo insensible -a menudo desapercibido- de nuestra vida emocional, así como su fluidez, su fragilidad, y su pulsación propia ${ }^{38}$. Este autor, en referencia explícita a Bergson ${ }^{39}$, destaca la génesis pasiva de cada emoción, subrayando su acontecer y su emergencia a cada instante renovada y sin embargo imposible de aprehender; por otro lado, volviendo a $\mathrm{V}$. Woolf y a W. James ${ }^{40}$, señala la fluctuación y movilidad constantes de la emoción. Estos rasgos, no obstante, se desprenden tardía y marginalmente sobre el fondo de un análisis de la espacialidad corporal entendida como campo de fuerzas kinestésicas.

Según lo dicho hasta ahora, podemos concluir que la temporalidad emocional encierra los siguientes rasgos específicos: 1) a diferencia del afecto o la afección, que se impone y se revela en mí de un modo brutal, suscitando una repentina toma de conciencia, la emoción bien podría permanecer en el ámbito de lo pre-consciente: la emoción está ahí, pero todavía no la he destacado como tal; ella impregna mis palabras y mis gestos, e incluso el tono de mi voz, pero se mantiene como una base continua de mis actividades, y pasa las más de las veces desapercibida: yo vivo una emoción antes de apercibirla como tal. Por ejemplo, yo me encuentro invadida por un deseo amoroso que sin embargo no reconozco, el cual solo se volverá objeto de una toma de conciencia con motivo de un acontecimiento añadido que lo destaque, bien sea un accidente, un alejamiento, una ausencia, una desaparición. 2) A diferencia de la afección, que se da de un solo golpe $y$ en un instante, nuestro régimen emocional es fluyente [fluctuant], cambiante, hecho de variaciones infinitesimales, de lo que se sigue

37 Aunque el aburrimiento (ennui) sea analizado por Heidegger (cfr. Grundbegriffe der Metaphysik. Welt-Endlichkeit-Einsamkeit, GA 29/30, § 38 especialmente) como una Stimmung, no del acontecer [événementialité] y del instante sino de la duración y de la lentitud, del ensanchamiento del tiempo (lit. Langeweile) -el aburrimiento profundo resulta del ser temporal como tal, que suscita un vacío provocado por el hecho cotidiano de encontrarse "trouver le temps long"-, su reconducción a una forma de temporalidad distinta de aquella del acontecimiento no conduce al autor, curiosamente, a un análisis de la emotividad como tal.

${ }^{38}$ Glen A. Mazis, "Merleau-Ponty, Inhabitation and the Emotions", en Henry Pietersma (ed.), Merleau-Ponty. Critical Essays, Washington, D.C. / Lanham, MD, The Center for Avanced Research in Phenomenology / University Press of America, 1989; y sobre todo Emotion and Embodiment: Fragile Ontology, New York, Peter Lang, 1993.

39 Ibidem, p. 261 y pp. 266s.

40 Ibidem, p. 263. 
que cada emoción es extremadamente fugaz, y muy difícil, por tanto, de captar en sí misma. En otros términos, el afecto parte el tiempo en dos, mientras que la emoción posee la cualidad continua de una duración conformada por ínfimas variaciones. Durante la audición de una pieza musical en una sala de conciertos paso insensiblemente por toda una serie de registros emocionales: placer difuso, comodidad, incomodidad, irritación, tranquilidad, serenidad, alegría contenida, etc. Al compás de los movimientos de la pieza se perfilan, por un lado, los rasgos de mis reacciones de placer o de disgusto; por otro, se va formando el juicio estético que yo habré de sostener al acabar la función, cuando, con toda seguridad, alguien me pregunte si me ha gustado la obra.

Los encuentros intersubjetivos y estéticos parecen particularmente apropiados para despertar y favorecer nuestra condición emocional ${ }^{41}$, la movilidad fluyente y sin cesar renovada de nuestros sentimientos. Pero, ¿qué es, a fin de cuentas, lo específico de esta movilidad? ¿En qué medida no puede ser confundida con la motricidad kinestésica pulsional? ¿Hasta qué punto nos encontramos, en la movilidad emocional, con una dinámica estructurada, y cómo sería ésta?

C. La singularidad "cardial" de la movilidad emocional: la hipótesis de una doble analogía.

Apoyándonos en la frágil y lábil temporalidad del registro emocional, vamos a interesarnos ahora por la estructura de una tal movilidad. Es aquí donde, a nuestro juicio, se encuentra el punto álgido [point d'orgue] del análisis. En efecto, sería fácil pensar que esta vibración móvil de todos los instantes de una vida se da como un puro flujo caótico y disperso, desprovisto de toda forma de centración. Ciertamente, lo que nos es dado, es decir, lo que sentimos a título

\footnotetext{
${ }^{41}$ Los campos de la ética y de la estética suministran, lo hemos visto, unos soportes ejemplares de descripción de la emoción, pero permanecen como ejemplos que no agotan la estructura fenomenal de ésta. Desde este punto de vista, empatía y comprensión (cfr. sobre este punto, Hua XIV, no $13, \S \S 10$ y 11) son las experiencias determinantes de donde emana la emoción, sea ésta estética o amorosa. La cuestión primera es entonces la siguiente: ¿podemos estar emocionados, conmovidos, estando solos? Si éste no es el caso, ¿es que es siempre el otro [autrui] el que sirve directamente de revelador emocional? En la experiencia estética nos encontramos ya con una forma más indirecta de alteridad. En todo caso, convendría distinguir diferentes formas de alteridad, incluso de intersubjetividad, para evaluar mejor la pertinencia de una tesis de estas características (cfr. sobre este punto Pierre Kaufmann, L'expérience émotionnelle de l'espace, Paris, Vrin, 1987 y, a título de estadio anterior, cfr. también Alfred Schütz, "Making Music Together: A Study in Social Relationschips", en Collected Papers II, Den Haag, M. Nijhoff, 1964 , pp. 159-179, donde se describe la parificación husserliana (Paarung) como una matriz conjuntamente musical (resonancia vibratori) e intersubjetiva (empática). Cfr. sobre este punto el artículo consagrado a "L'arc-en ciel des émotions", escrito conjuntamente por Natalie Depraz y Francisco Varela.
} 
de la vivencia que aparece, es en buena medida una vibración que la mayoría de las veces es casi insensible. A este respecto es manifiesto que MerleauPonty, notablemente en Le visible et l'invisible, ha elaborado una asombrosa riqueza de vocabulario para tratar de describir tal movilidad. Basta pensar en los términos de "agitado" ["bougé"], de "carne" ["chair"], de "vibración" ["vibration"], de "entrelazado" ["entrelacs"], de "intrusión" ["empiètement"].

Sin embargo, esta micro-fenomenalidad de la que Merleau-Ponty da cuenta minuciosamente y con mucho detalle, extrayendo una riqueza y una densidad excepcionales que son consecuencia de prestar atención al lenguaje y a sus recursos infinitos, sean literarios o poéticos, no permite esclarecer de manera analítica la estructuración - que con todo comprende la fluidez- de una movilidad de este tipo. Al leer algunos pasajes de su última obra, inacabada, podríamos acabar por pensar que lo "informe" es la cualidad primera de la emoción.

Ahora bien, aquello que yo quisiera tratar de mostrar es que las fluctuaciones emocionales, por muy vacilantes que éstas sean, contienen una forma estructural que puede ser analizada en sí misma, la cual, además, como dinámica específica, abraza toda vacilación emocional. Un análisis de este tipo implica interrogarse por el tipo de unidad, por el modo de unificación o de centración que rige la fluencia en cuestión. Dada su función operacional de estructuración del ritmo heterogéneo de las emociones, una unidad de este tipo no tendrá el mismo modo de aparecer de las diferentes emociones particulares, captadas precisamente en el tejido moviente de su transcurso fluyente [écoulement fluctuant]. Sin embargo, la centración en cuestión no es totalmente in-apareciente, es decir, cortada y como apartada de este ritmo plural, ya que ella tiene por virtud el estructurarlo. A título de polo de centración, ella toma prestados ciertos rasgos de su legalidad que son propios de la fluctuación emocional.

En otros términos, un tal centro no es trascendente a las emociones, ni es tampoco su condición trascendental formal de posibilidad, independiente de ellas y que se aplicaría en el modo del Yo [Je] puro de la apercepción kantiana o del yo [moi] husserliano como polo o punto focal estático de las vivencias psíquicas. Tal centro es a todas luces inmanente, sin que por ello se confunda ni con una vivencia singular cualquiera ni a fortiori con el órgano funcional de una tal vivencia - ya que esto vendría a inmanentizar a la inversa tal centro, al modo merleau-pontiano, hasta el punto de naturalizarlo, confiriéndole un tenor material de tipo orgánico, sobre el modo kinestético corporal-carnal del Leib. 
$\mathrm{Ni}$ trascendental, entonces, en el sentido de una condición a priori de posibilidad o en el sentido de una condición estática formal, ni inmanente hasta el punto de organizarse y naturalizarse. Este centro de las emociones corresponde a su misma dinámica de engendramiento, de emergencia y de vibración. Es, con justicia, trascendental, puesto que proporciona la regla unificada y constitutiva de su aparecer, pero en el sentido de una regulación dinámica que abraza su movilidad y su generación. Esto significa que un centro genético de las emociones como el que aquí se perfila no deja de descentrarse y de recentrarse, según un movimiento en parte aleatorio, a consecuencia del ritmo que da nacimiento, de modo pasivo, a nuestras emociones.

Nosotros quisiéramos ver en el corazón esta estructura dinámica de centración funcional de las emociones: del mismo modo que el yo (Ich) es aprehendido por Husserl de modo estático como el polo o centro de las vivencias psíquicas, y del mismo modo que el Leib es presentado como el foco y el centro genético de las kinestesias que lo irradian, el corazón [coeur] -ésta es al menos nuestra hipótesis de trabajo- se da como un foco [foyer] móvil, fluyente y refluyente; en definitiva, como la fuente de la que emergen las vivencias emocionales.

En este sentido nos encontramos con una doble analogía que articula estructuralmente y singulariza al mismo tiempo los tres centros funcionales en cuestión (Ich, Leib, coeur) y sus tipos de vivencias (físicas, kinestésicas motores / pulsionales, emocionales) en lo que respecta a su contenido; doble analogía que se presenta de la siguiente manera:

Primera analogía: el yo [moi] es a las vivencias psíquicas lo que el cuerpo es a las kinestesias motrices.

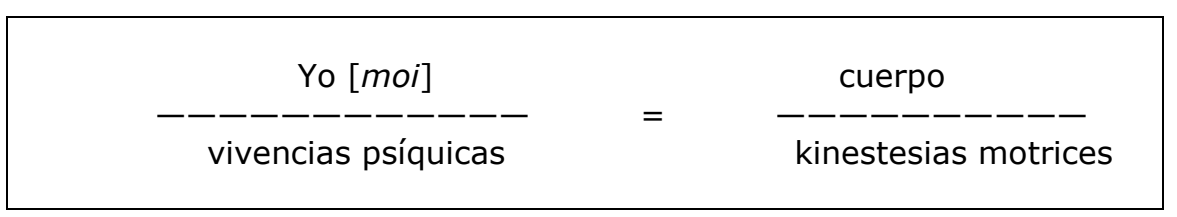

Esta analogía descansa en la relación estructural homóloga entre el yo y las vivencias psíquicas y entre el cuerpo y las kinestesias motrices. Tanto el yo como el cuerpo reciben el estatuto de centro funcional o de foco operacional del que parten, bajo la forma de un entramado de irradiaciones [réseau de rayons], 
en un caso de vivencias físicas, en el otro de kinestesias motrices ${ }^{42}$. En cambio, la diferencia, en lo que respecta al contenido, remite al proceso de inmanentización que va del yo al cuerpo. En otros términos, el centro cambia de sentido: de un centro yoico [égoïque], fijo y trascendente a la voluntad que rige las vivencias físicas, pasamos a un centro móvil, estructurado por movimientos sensibles inmanentes: las kinestesias motrices ${ }^{43}$. Aunque el enraizamiento corporal del yo entraña una cierta movilidad del centro encarnado, así como una inmanentización de los movimientos sensibles, este desplazamiento del ego voluntario al cuerpo receptivo no permite especificar la moción propia de la emoción, de donde se sigue la necesidad de poner en juego una segunda analogía.

Segunda analogía: el cuerpo vivo [literalmente "carne", chair] es a las kinestesias pulsionales lo que el corazón es a los movimientos emocionales vividos

\begin{tabular}{|cc|}
\hline cuerpo vivo [chair] \\
kinestesias pulsionales
\end{tabular}$\quad=\quad$\begin{tabular}{c} 
corazón \\
\hline
\end{tabular}

Lo que está en juego en esta analogía reside 1) en la articulación fina entre el movimiento corporal / carnal y el movimiento emocional, y 2) en la singularización de éste último. Procurando encontrar la homología más justa, conviene situar estos dos movimientos en un plano común, a saber, de tipo genético. De aquí la necesidad de hacer aparecer la conversión reductiva del cuerpo [orgánico, vivido] a la carne [chair, cuerpo vivo], es decir, de las kinestesias motrices a las kinestesias pulsionales. Desde esta perspectiva, el Leib juega un rol de interfaz entre el yo y el corazón, es decir, entre el carácter estático y el genético [staticité y genèse], del hecho de su doble constitución, corporal-motriz y carnal-pulsional $^{44}$. Pasamos también de una analogía a la otra al pasar de un centro estático (el ego / el cuerpo) a una centración genética (la "carne" / el corazón).

42 Cfr. Eduard Marbach, Das Problem des Ich in der Phänomenologie Husserls, Den Haag, M. Nijhoff, 1974.

${ }^{43}$ Cfr. Hua XV, Beil. XIX, ya citado, y que describe este paso del yo de la voluntad al yo encarnado, así como el cambio de relación que se establece entre el centro y las vivencias irradiantes, subordinados en el caso del yo, efectivos en el caso del cuerpo.

${ }^{44}$ Cfr. desde esta perspectiva, Natalie Depraz, "La traduction de Leib, une crux phaenomenologica", Etudes phénoménologiques 4 (1997). 
La homología estructural de esta segunda analogía reside en esta genetización del centro carnal como "cardial", que confiere tanto a las kinestesias pulsionales como a las "mociones" emocionales vividas un rol de participación constitutiva en el proceso de centración, asegurándose su dinámica de descentramiento y de re-centramiento incesantes ${ }^{45}$. La singularidad de los movimientos emocionales reside en su estatuto mediador entre la motricidad corporal y la pulsionalidad carnal, por la cual el corazón se sitúa entre el cuerpo egoizado [égoïsé] y la "carne" pulsional en el orden de la inmanentización del ego ${ }^{46}$. Se sigue de aquí la necesidad de presentar nuestra hipótesis analógica de otro modo, de un lado bajo una forma no ya doble sino triple, y, del otro, acentuando el modo de circulación entre todas las analogías:

Primera analogía:

$\begin{array}{cc}\text { cuerpo } \\ \text { "carne" }\end{array} \quad=\quad \begin{gathered}\text { kinestesias motrices } \\ \text { kinestesias pulsionales }\end{gathered}$

Segunda analogía:

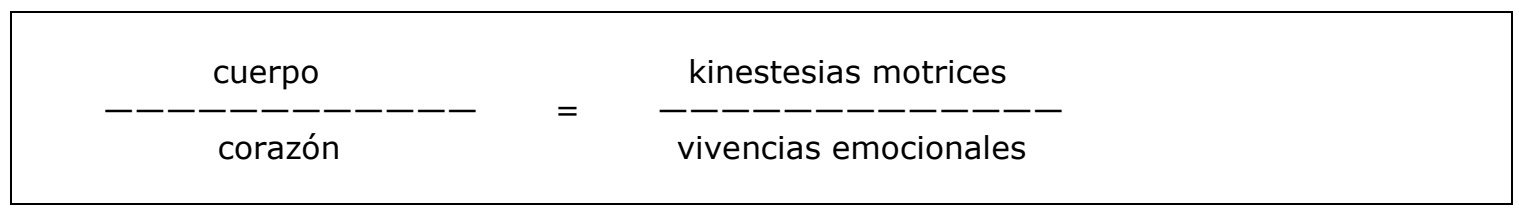

Tercera analogía:

\begin{tabular}{cc|} 
corazón & vivencias emocionales \\
"carne» & $=\quad--------1$ \\
kinestesias pulsionales
\end{tabular}

La primera presentación de las dos analogías permanece en un plano estático, en el sentido de que cada nivel de estructuración entre centro e irradiación vivida permanece excluido del otro.

${ }^{45}$ Estoy agradecida a Caroline Gros, quien, durante la sesión de noviembre de 1997 del Seminario conjunto Daseinsanalyse/Alter (ENS), en el curso de la cual fue presentada una primera versión de este texto, llamó mi atención sobre esta dinámica de la centración.

${ }_{46}$ Recordamos que el thumos platónico cumple una función mediadora homóloga entre regulación de los deseos (de las pulsiones carnales), l'epithymeticon, y asistencia del espíritu (ego encarnado), le nous, en su canalización. El corazón tímico tiene desde entonces un estatuto bi-fronte, dando lugar bien sea al amor si éste está unido al deseo pulsional, bien sea al valor si se vuelve sobre el espíritu encarnado (cfr. nota 9, in supra). 


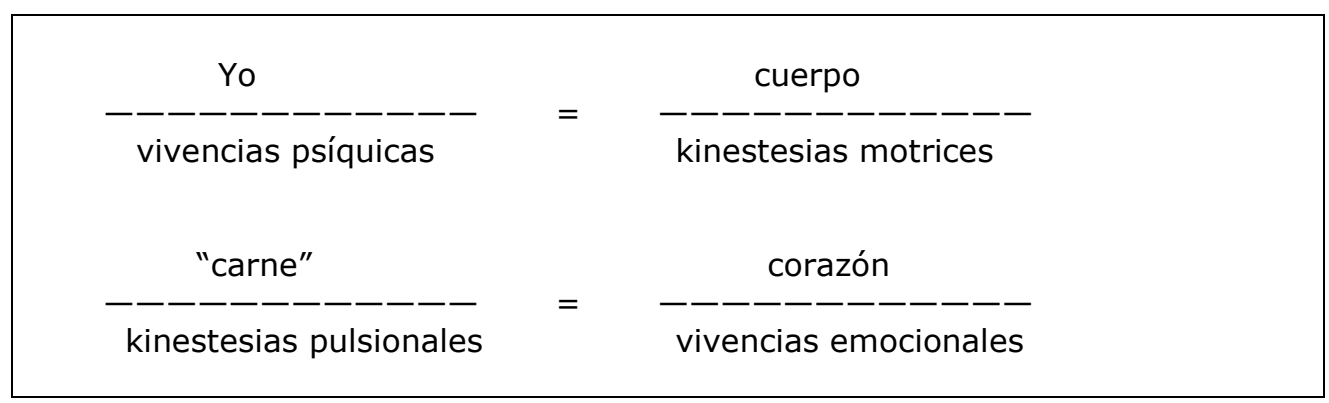

En cambio, la segunda presentación analógica no solo permite situar con más acierto lo emocional cardial dando lugar al pasaje del cuerpo motor a la "carne" pulsional -o inversamente, al proceso que media entre la generación de la pulsionalidad carnal y la motricidad orgánica-, sino que, debido a su estructura entrelazada, anima una dinámica de este tipo.

D. La génesis emergente de las vivencias emocionales desde la organicidad del corazón.

Para situar más precisamente el nivel de inmanencia fenomenológica del movimiento emocional y de su foco generador -el corazón-, conviene, por último, apoyarse en la elucidación de la emoción tal y como se propone en algunos trabajos contemporáneos de neurobiología, los cuales, sin llevarnos a una naturalización ingenua de la descripción fenomenológica, permiten sin duda afinar la fenomenalidad misma, con el fin de resaltar, con la vista puesta en la emoción, su singularidad fenomenal.

Bien entendido, el corazón -Husserl lo notaba rápidamente en 1911, en los Grundprobleme der Phänomenologie- no es en ningún modo reductible al órgano que juega el rol de una bomba casi mecánica que activa la circulación de la sangre y la conduce al cerebro: "La alegría y la tristeza no están en el corazón como la sangre está en el corazón; las sensaciones táctiles no están en la piel como los fragmentos de su tejido orgánico"${ }^{\prime 47}$. Esto equivaldría a naturalizar indebidamente el corazón, a exponerse a las duras críticas de reduccionismo organicista, y a eliminar la discontinuidad fenomenológica decisiva entre el nivel de la vivencia emocional y el nivel estrictamente orgánico. En este mismo sentido, la lengua alemana no se ha equivocado $y$, a diferencia del

${ }^{47}$ Hua XIII, no 6, § 3, p. 115. 
francés o del inglés, dispone de dos términos distintos, uno para nombrar el órgano (Herz), otro para referirse a la vivencia cardial (Gemüt) ${ }^{48}$, respetando así una discontinuidad isomórfica, necesaria de tipo funcional, pero insuficiente.

En efecto, la pulsación del corazón, su ritmo, su vibración incesante, la sensación invisible y desapercibida, tal y como lo nota Merleau-Ponty en la Fenomenología de la percepción, es la dinámica misma de impulsión y emergencia de las vivencias emocionales. Se trata entonces de un centro de movilidad incesante que, aún estando orgánicamente localizado, resalta una estructura cuya pulsación inmanente conduce a su descentración y a su deslocalización, sin por ello desestructurarse: la intensidad del ritmo cardíaco soporta los flujos y reflujos a menudo incontrolables y cuya elasticidad es por momentos insospechada. Desde esta perspectiva, la movilidad de la vivencia emocional abraza y resuena a la vez sobre este juego de descentramiento y de re-centración del que está hecho el corazón, según una inter-acción co-generativa ${ }^{49}$.

Con ello se quiere decir que, al lado de la discontinuidad metódica esencial que hay entre la organicidad del corazón y la vivencia emocional -la cual permanece estática-, la legalidad genética de aparición móvil del movimiento de la emoción sobre la base de un ritmo cardiaco él mismo incesante -que se recentra al descentrarse- parece afinar mucho mejor la descripción del nacimiento mismo de la emoción. Es lo que la fenomenología genética de las emociones formula en términos de autoconstitución genética: la vivencia intencional se engendra desde la heterogeneidad tímica del ritmo fluyente del corazón, permaneciendo en todo momento irreductible en tanto que vivencia. Las ciencias cognitivas formulan hoy esta dinámica en los términos de una emergencia de la emoción, como vivencia cognitiva singular y sobre la base de la compleja red interactiva y auto-reguladora del sistema inmunitario, limpático y tímico ${ }^{50}$.

Así, tanto en la descripción fenomenológica de la génesis de las emociones como en la modelización emergentista de su acontecer, está en juego la doble

${ }^{48}$ Cfr. Stephan Strasser, Das Gemüt, op. cit.

49 En lo concerniente a estos tres modos de articulación metódica posibles entre fenomenología trascendental y ciencia empírica (1. reduccionismo naturalizante; 2. discontinuidad isomórfica funcional; 3. inter-actividad co-generativa), de los cuales solo el último es plenamente satisfactorio, cfr. Francisco Varela, "The Naturalization of Phenomenology as the Transcendance of Nature. Searching for generative mutual constraints", Alter 5 (1997) 355-381, y Natalie Depraz, "When Transcendantal Genesis Encounters the Naturalization Projet", en Jean Petitot et al. (eds), Naturalizing Phenomenology: Issues in Contemporary Phenomenology and Cognitive Science, Stanford, Stanford University Press, 1999.

${ }^{50}$ Cfr. sobre este punto Francisco Varela, "The Body's Self", en Daniel Goleman (ed.), Healing Emotions, op. cit. 
exigencia: 1) de su dinámica inmanente, enraizada en la organicidad de nuestro cuerpo y a una con ello en el "cuerpo de nuestro cuerpo", el corazón; 2) de su irreductibilidad a la base orgánica, por el hecho de su globalidad no descomponible y no redistribuible en partes / propiedades locales. La movilidad fenomenal propia de la emoción se diferencia, en razón de su no-intencionalidad pasiva, y como tal no localizable, de las vivencias kinestéticas motoras. De igual modo, las células simpáticas se caracterizan, a diferencia de las células nerviosas, por su movilidad incesante no-localizable, ya que aquéllas están en circulación perpetua, regenerándose continuamente. Estos dos rasgos estructurales comunes, 1) ilocalización; 2) movilidad incesante, vienen así a alimentar una última hipótesis analógica: las vivencias emocionales son al Gëmut lo que las células simpáticas son al Herz ${ }^{51}$.

Traducido del francés por Roberto C. F. Menéndez

${ }^{51}$ Para una prolongación de este método co-generativo a propósito de la emoción, y para una comprensión correlativa de la fluctuación cordial en términos de "valencia", cfr. Francisco Varela / Natalie Depraz, "At the Source of Time: Valence and the Constitucional Dynamics of Affect", Journal of Consciousness Studies vol. 12, 8-10 (2005) 61-81. 